\title{
A COUSA NÃO FOI ASSIM, FOI PIOR: SEIQUE, DE SUSANA SÁNCHEZ ARINS E A (DES)MEMÓRIA DA REPRESSÃO FRANQUISTA NA GALIZA
}

NO FUE ASÍ, FUE PEOR: SEIQUE, DE SUSANA SÁNCHEZ ARINS Y LA (DES)MEMORIA DE LA REPRESIÓN FRANOUISTA EN GALICIA

Joyce Rodrigues FerrazInfante*

Resumo: O objetivo deste trabalho é demonstrar como a escritora galega Susana Sánchez Arins, por meio de uma escritura fragmentada constrói em seique uma por meio de uma escritura mórias do constró em seique uma narrativa que recupera meque havia sido um dos mais temidos repressores franquistas da região de Pontevedra, Galiza. A partir de uma contextualização sobre a história da Galiza nos primeiros meses do golpe de estado de 1936, taça o dos modos de apreensá do conhecimento historico por meio da histora oral, da convive do conhecime famillo histónico por meio da história oral, da convivência familiar e comunitária, além do que se obtém por meio do acesso a documentos e arquivos.

PALAVRAS-CHAVE: Literatura galega contemporânea; Literatura espanhola contemporânea; Memoria, Historia. ferrazrj@ufscar.br

Profa. Dra. Joyce Rodrigues Ferraz Infante. Departamento de LetrasDL. Programa de Pós-Graduação em Estudos de Literatura-PPGLit. Universidade Federal de São Carlos-UFSCar.

Resumen: El objetivo de este trabajo es demostrar cómo la escritora gallega Susana Sánchez Arins, por medio de una escritua fragmentada, contruye en seique una narración que recuper las memorias del pasado familiar para contar la historia de un tío abuelo que había sido uno de los represores franquistas más temidos de la región de Pontevedra, Galicia. A partir de una contextualización de la historia de Galicia en los primeros meses del golpe de estado de 1936, se elabora la presentación de los helex to de Sánchez Arins y percibir su capacidad de configurar un una representación de las formas de aprehender el conocimiento histórico por medio de la historia oral, de la convivencia familia y comunitaria, además de lo que se obtiene a través del acceso a documentos y archivos.

PALABRAS CLAVE: Literatura gallega contemporánea; Literatura española contemporánea; Memoria; Historia. 


\section{Carapuchinha}

Para Pilar, que tem feito esta viagem quando nena

1. A Radio Nacional de España (RNE) foi fundada em $1937 \mathrm{com}$ o proposito de divulgar informações e propaganda do bando franquista durante a guerra civil na ditadura conteúdos e noticias oficiais. Atualmente, a RNE integra a Radiotelevisión España (RTVE) corporação que gere os canais de rádio e televisão estatais na Espanha.

2. A referência ao "Ejército Rojo" Exército Vermelho - e uma clara alusão à derrota, na Espanha, do avance soviético, uma vez que, segundo a propaganda do bando de Francisco Franco, o projeto da II República era fazer da Espanha uma extensão da Rússia. Lembrese que após a Revolução de 1917 Trotsky organiza o "Exército Vermelho" dos operários e dos camponeses para combater as forças antibolcheviques durante a guerra civil que se seguiu à Vermşo. Em 1921 Exército foi nos tempos de maria castanha

outra manhá o mesmo caminh que vaia a meninha com a sua candur e uma cestinha de viandas atestad pão de boroa pisca de toucinho um caldinho que há chegar morno

e outra manhá o dia nascendo sair do rueiro laganhas nos olhos passar rente o moinho e seguir o peso da cesta um golo na font os pés de lama cobertos espidos e outra manhá chegar a cesantes e buscar barqueiro que cruze o mar

há em sam simão preso o avó camisas azuis vestem os lobo

Susana Sánchez Arins) apanhar umas flores a marela

\section{HISTÓRIA..}

No dia primeiro de abril de 1939, o general Francisco Franco mandava divulgar pela Radio Nacional de España ${ }^{1}$ um breve comunicado que informava à sociedade espanhola a vitória das tropas nacionais sobre o "Ejército Rojo"2 e, consequentemente, o fim da Guerra Civil. ${ }^{3}$ Apesar dessa declaração, pode-se dizer que a guerra se prolongaria na forma de guerrilha e resistência por parte de republicanos que, na clandestinidade, praticaram oposição ao governo franquista pelo menos até 1949 , quando se decretou o final do "estado de guerra". A ditadura instituída por Franco, em seus quase quarenta anos de existência, combateu duramente os opositores mediante uma política do terror, fortemente repressiva, punitiva e excludente. Durante a Guerra Civil e o pós-guerra, a opressão franquista foi sistematicamente organizada por meio de conexões e interrelações políticas, militares, religiosas, socioculturais, cujo objetivo era expurgar da sociedade todas as ideias e pessoas - independentemente de idade, gênero, classe social, nível de educação - que participaram da II República ou a defenderam, de forma ativa ou passiva, as quais representavam perigo para a "Nova Espanha". No entanto, não bastava eliminar fisicamente os inimigos em sessões de fuzilamento ou condená-los à prisão ${ }^{4}$, também era necessário reeducar a população desafeta, ou suspeita de o ser, ao regime
3. Transcrição do comunicado: "En e dia de hoy, cautivo y desarmado el Ejército Rojo, han alcanzado las tropas nacionales sus últimos objetivos militares. La guerra ha terminado. El Generalisimo Franco. Burgos, $1^{\circ}$ de abril de 1939." gravação original da emissão radiofônica está disponível em http://www.rtve.es/alacarta/ audios/80-anos-de-la-guerra-civil/

parte-oficial-victoria-del-ejercito-

4. De acordo com o historiador Gutmaro Gómez Bravo, a prisão franquista, para além da repressão, tinha como função a reeducação patriótica e religiosa das presas e presos políticos. Construido como um modelo desumano de disciplina militar e marco jurídico confessional, a fase penitenciária do imediato pós-guerra e da década de 1940 implicou a íntima fusão de elementos nacionalistas e católicos tradicionais com base na ideia de redenção. 
5. A Ley de Responsabilidades Políticas, de 9 de fevereiro de 1939, serviria para "liquidar las por quienes contribuyeron con actos u omisiones graves a forja a sublevación roja"; a Ley sobre la Represión de la Masonería y del Comunismo, de 1 de março de 1940, criminaliza o comunismo, a maçonaria e demais organizações as quais, contrárias à ordem social e ao "Movimiento Nacional",

conduziram a Espanha à "terrible campaña atea, materialista,

antimilitarista y antiespañola".

onte: Boletín Oficial del Estado (www.boe.es). de Franco, de forma a criar em todo o território espanhol um consenso forçado (ARNABAT MATA, 2013, p.35), ou seja, uma impressão de total concordância de opiniões, pensamentos, crenças, sentimentos para com o governo franquista. Com propósitos de controle, reeducação e apagamento da memória republicana, a política de repressão contra os vencidos - na forma de torturas, detenções, fuzilamentos, desaparecimentos, vigilância, incentivo à delação, censura, alienação cultural, evangelização compulsória -, amparada por leis como a de Responsabilidades Políticas, de 1939, ou a de Represión de la Masonería y del Comunismo, de $1940^{5}$, produziu na sociedade um sentimento generalizado de medo e impotência, que levou parte da população a proteger-se no silêncio e na dissimulação de pensamentos, sentimentos, crenças que pudessem ser consideradas dissonantes em relação ao regime franquista.

As estratégias repressivas que se disseminariam por todo o país teriam sido testadas, primeiro, na Galiza, onde praticamente não houve conflito armado devido à rapidez com que triunfou ali o golpe de estado. Os métodos de usurpação do poder administrativo de mãos $\boldsymbol{d a}$ esquerda e de eliminação massiva de pessoas por motivos políticos utilizados nos municípios galegos pelos sublevados - militares e civis - com o único objetivo de "acabar con el sistema político legal, incluso con una cultura política, para imponer otro más acorde con los intereses de los perdedores de las elecciones de febrero de 1936" (ESPINOSA MAESTRE apud ZUBIAGA ARANA, p.23) seriam impostos progressivamente nos territórios ocupados pelo exército Nacional durante a Guerra Civil e o pós-guerra. Nesse sentido, a Galiza teria funcionado como um laboratório de experimentação das táticas de repressão e controle político e social. Segundo o historiador Emilio Grandío (2001, p.215216), às vésperas das eleições de fevereiro de 1936, o então general Francisco Franco - galego nascido em Ferrol que ocupava o cargo de General Jefe del Estado Mayor Central da II República, prevendo a vitória da esquerda, a Frente Popular, planejou na sede da Región Militar em A Corunha juntamente com outros militares do alto escalão das forças armadas espanholas a ação inicialmente denominada "Movimiento Nacional", cujo objetivo era resgatar a Espanha das mãos daqueles que - de acordo com os militares - pretendiam desuni-la para entregá-la aos sovietes. Iniciado entre 17 e 18 de julho de 1936, o "Movimento", ou melhor, o golpe de estado contra a II República, consolidou-se em poucos dias na Galiza, uma vez que contou com o apoio das tropas galegas aquarteladas para tomar o poder nas localidades administradas pela esquerda republicana. A usurpação do poder deu-se

EM TESE $\quad$ BELO HORIZONTE $\quad$ v. $26 \quad$ N. $2 \quad$ MAO-AGo. $2020 \quad$ FERRAZ-INFANTE. A cousa não foi assim, foi pior: seique [...]


6. O termo "passeio" - "paseo", em espanhol - designa de forma eufemística uma corriqueira prática de repressão política realizada nos anos da Guerra Civil Espanhola do pos-guerra que consistia em buscar a vitima - geralmente em sua casa - com a "desculpa" de levá-la para dar um passeio, o qual terminava em fuzilamento em algum lugar ermo ou nos arredores nos primeiros dias do golpe, pela detenção e fuzilamento sumário de líderes políticos, prefeitos, governadores, vereadores de esquerda, e nas semanas seguintes, pela intensidade e violência da repressão contra qualquer pessoa suspeita de participar de forma ativa ou passiva da II República ou de cultivar ideias e ideais considerados "marxistas", os quais representavam uma ameaça para a Espanha católica e tradicional e, portanto, deviam ser extirpados. A campanha maniqueísta que opunha a "Espanha" à "Anti-Espanha" foi bastante efetiva nesse período, e não apenas conseguiu obter a conivência de parte da população conservadora, como a transformou em colaboradora e aliada no processo de limpeza de costumes e higienização ideológica, tão necessário para o surgimento da "Nova Espanha". A desmesurada violência praticada pelos sublevados - "passeios", torturas, desaparecimentos e mortes; delações ou denúncias; ameaças e humilhações públicas -, que durante anos infundiu a sensação de "terror" e "medo" na população, foi, sem dúvida, uma das principais estratégias do Exército Nacional para imobilizar e controlar seus opositores. As bases do regime franquista, que se aplicaram ao longo de décadas em todo o território espanhol, cimentaram-se, segundo Grandío (2001, p. 222), na Galiza.
Passados mais de oitenta anos da emissão do comunicado radiofônico de Francisco Franco e quarenta e cinco anos da morte do ditador, o país vive uma democracia que, para consolidar-se, fez um pacto de anistia extensivo a todas as pessoas que cometeram crimes políticos em prol da ditadura de Franco ou contra ela, com vistas ao perdão recíproco e ao esquecimento do traumático passado recente. Essa tentativa política de esquecimento ou amnésia que prescindia da reparação mínima às vítimas e seus familiares, aos que ainda buscavam os seus mortos e desaparecidos, aos exilados, aos silenciados, perdurou, de acordo com Mercedes Yusta Rodrigo (2014), até o ano 2000, quando a sociedade espanhola experimentou uma catarse coletiva perante as evidências das atrocidades cometidas pelo franquismo quando fossas comuns foram abertas pelos movimentos de "recuperação da memória histórica", dando claras mostras de que o passado - que se queria superado - faz-se presente na Espanha atual. Para a historiadora, ainda que o problema da memória histórica seja fundamentalmente político, discutir o passado a partir de diferentes perspectivas - historiográfica, judicial, artística -, é importante para torná-lo mais compreensível (YUSTA RODRIGO, 2014, p. 41).

Em 22 de outubro de 2009, o jornal El País/Galicia dava notícia do resgate dos restos mortais de duas vítimas 
da repressão contra republicanos praticada na Galiza, no município de Cambados, em Pontevedra, nos primeiros meses do golpe. Segundo a reportagem, os dois jovens, de 19 e 27 anos, antes de serem assassinados, foram torturados e suas famílias, humilhadas tendo sido a mãe de um deles também estuprada. A exumação foi acompanhada pela irmã de um dos mortos, Josefina, uma senhora de 83 anos, que indicou aos arqueólogos o local da fossa. Em 15 de setembro de 1936, a menina de 9 anos testemunhou a prisão do irmão, levado de casa por falangistas, e dado, depois, por desaparecido. No município se sabia que havia sido fuzilado e se conhecia o local do enterramento, no entanto, a família teve de calar-se e esperar 73 anos para sepultá-lo. Josefina recorda as circunstâncias que envolveram o assassinato do irmão:

Mi padre les pidió que le hicieran a él lo que quisieran, pero que no molestaran a su familia. Pero sacaron a mis hermanas y las hicieron bailar desnudas delante de ellos, [...]. Sufrimos muchísimo. Mi madre no se quitó el luto por su hijo hasta que murió. Los dos murieron con esa amargura, pensando siempre en el hijo que le habían matado. Pa rece que estuviera viendo ahora a mi hermano: era un hombre como un castillo, fuerte, bueno... (JUNQUEIRA, 2009)
A notícia da escavação da fossa de Cambados parece ter sido um dos impulsos que levaram a escritora e professora de literatura Susana Sánchez Arins a remexer no passado, vasculhar recordações e memórias familiares, consultar antigos jornais e arquivos para contar a história de um de seus antepassados, o tio-avô Manuel García Sampayo, que teria sido um dos principais repressores da região de Pontevedra, onde vivia. Segundo Susana, em entrevista para Tereixa Constenla, do suplemento Cultura, de El Pais:

En Cambados habían excavado una fosa, una de las primeras de Galicia, y uno de mis alumnos contó en el aula que era descendiente de una de las víctimas. El resto de la clase no creía que pudieran haber asesinado a alguien. Pensé que no estaba bien que ignorasen su propia historia y también pensé que $\mathrm{mi}$ tío abuelo podría haber asesinado al antepasado de mi alumno porque la fosa estaba cerca de la casa familiar de Portarís. (apud Constenla, 2019)

Movida pela necessidade de ajustar contas com um antepassado repressor que, apesar dos crimes, gozava do privilégio do anonimato, Susana Sánchez Arins escreveu o livro seique - cujo original em língua galega publicado em 2015 foi traduzido por ela mesma para o castelha no em 2019, sob o título Dicen -. Em outubro 
7. Entrevista para a página literária Lecturafilia em 02/06/2018. Disponível em: lecturafilia.com/tag/ entrevista-susana-sanchez-arins/ de 2019, Susana publica a segunda edição galega do seu livro, revista e ampliada. A segunda edição de seique surgiu, sobretudo, da repercussão que o livro teve no a mbiente familiar, em Pontevedra - onde ocorrem os acontecimentos mencionados na narrativa -, e em toda a Espanha - depois de publicada a versão em castelhano. A a utora ouviu dos leitores - incluídos alguns parentes e pesquisadores da repressão na Galiza -, novos detalhes e outras versões das histórias que conta na primeira edição e incorporou à nova edição boa parte desse material:

caixa de pandora

decido continuar a escrita. apesar de perdas e danos. no fundo, um confiar na força da palavra: que este abrir de portas a nime outras vozes a exporem íntimas estórias e privadas. que assomem às varandas da memória e bradem. que esta não seja outra cousa que uma narrativa em construção porque atrás das vozes vêm vozes e outras vozes hão de vir.

nunca pensei que tal fosse acontecer. (SÁNCHEZ ARINS, 2019, p.79)

Para além do objetivo inicial de ajustar contas com um repressor franquista e de retirá-lo do privilégio do esquecimento, seique, segundo a própria autora, numa entrevista ${ }^{7}$, dignifica a memória oral, expõe as repressões familiares, denuncia as violências e humilhações contra mulheres, enobrece o saber popular e a arte de contar..

Susana Sánchez Arins pertence à geração de escritores conhecida como os "netos da guerra", autores que nasceram no final da ditadura ou já no período democrático. Esse grupo de narradores mais recentes, de acordo com Dolores Vilavedra,

será capaz de encontrar un singular equilibrio entre la verdad empírica, contemplada siempre en su dimensión más humana y que les sirve a menudo como punto de partida, y su libérrimo desarrollo literario. Esta posición debe interpretarse desde la perentoria necesidad de entender el pasado, de recuperarlo en una lucha contra el reloj biológico que avanzaba implacable para los que había sido los protagonistas de la guerra, y la conciencia de que el tema podía servir de punto de encuentro intergeneracional, la convicción de que la guerra era el eslabón perdido que podía soldar ese hia to histórico. No se trataba de hacer justicia pero sí de un acto de reparación [...], en la medida en que hacía visibles episodios y personajes que, si no fuese por su resurrección literaria, quedarían sepultados por la desmemoria. Así, si en muchos casos la realidad es un punto de partida, su desarrollo ficcional se convierte en un acto de protesta y una toma de posición ética. (2011, p.13) 
8. Para a Associaçom Galega da Língua, AGAL, a estratégia reintegracionista ou luso-brasileira para o galego trabalha sobre a base de que a Galiza, Portugal e língua, na Galiza gla, português.

9. Trata-se de uma proposta de lei de iniciativa popular - a $L e i$ $n^{\circ}$ 1/2014, do 24 de marzo, para o aproveitamento da lingua portuguesa e vinculos coa lusofonía - para potenciar a língua portuguesa na Galiza, região autónoma espanhola. A oferta da língua portuguesa na rede de ensino e seu reconhecimento no acesso à função pública.
Nesse sentido, a literatura sobre o tema, publicada na Espanha nos últimos anos, ao integrar testemunho, memória e história, colabora com as reivindicações de verdade relacionadas aos traumas advindos da violência que se instaurou no país a partir do golpe de estado de 1936 os quais, apesar do tempo transcorrido, continuam latentes e presentes não apenas na vida dos que viveram os eventos, mas ta mbém dos descendentes que, para além de justiça, indaga m sobre vazios, silêncios, rupturas, incógnitas que conforma m sua identidade fa miliar, individua e coletiva. Escrever para contar e, de alguma maneira para tentar explicar e compreender o passado, sem abrir mão do valor estético do texto literário, é a intenção dos autores desta geração.

\section{MEMORIA E LITERATURA...}

A galega Susana Sánchez Arins nasceu em 1974, em Vilagarcía de Arousa, cresceu em O Foxo, interior da província de Pontevedra e, atualmente, concilia as carreiras de professora de ensino secundário nA Isla de Arousa e a de escritora. Sánchez Arins iniciou-se no mundo das letras como o poemá rio [de]construçom (2009), ao qual seguira m-se aquiltadas (2012), a noiva e o navio (2012), carne da minha carne (2018) e as narrativas seique (2015) e tu contas e eu conto (2018); além de dicen (2019), tradução ao castelha no de seique; e a segunda edição de seique (2019), revista e ampliada. Susana se reconhece como mulher, de aldeia e galega, três identidades que marca m com força a sua personalidade - e a de sua escritura -, a qual se faz notar em sua postura de autora reintegracionista ${ }^{8}$, ao compartilhar a ideia de que o galego e o português são variantes da mesma língua:

E para mim a via lusófona é a via do enriquecimento. Temos através dela, acesso a toda uma diversidade de mundos e vozes que, muitas vezes, nos devolvem a nossa própria realidade espelhada. Eu adoro descubrir em leituras angolanas ou brasileiras (que consigo realizar com bem pouco treino ortográfico) as palavrinhas da minha aldeia, aquelas que os dicionários me dizem serem localismos. Localismos meus e paulistas e lua ndinos. E adoro chegar através da lusofonia a essas muitas outras línguas pequenas, em perigo bem mais grande que a nossa, que povoam as terras moçambicanas ou as beiras do Amazonas. Gostava de que todas as pessoas da minha comunidade gozassem como eu gozo esse direito de ver-se no mundo. Por isso gostava de que a Lei Valentín Paz-Andrade ${ }^{9}$ virasse realidade. E que a estratégia reintegracionista fosse aceitada polas instituições. (SÁNCHEZ ARINS apud TORRES, 2015)

Por meio de uma linguagem que utiliza recursos poéticos como a elipse, a concisão, a seleção lexical sugestiva e ritmos verbais capazes de transmitir a sensação da 
10. Daqui em diante, nas citações com menos de tres linhas do livro seique (2019), de Susana Sánchez Arins, constara apenas a página da qual provém o excerto. oralidade, Susa na Sánchez Aríns constrói, em seique, com uma sensibilidade de espectro afetivo largo, que inclui desde a delicadeza até a contundência, uma narrativa que reconfigura pedaços de vida de pessoas comuns, anónimas, insignificantes, e que ao mesmo tempo compõe uma reflexão sobre memória, desmemória e sobre maneiras de contar, de escrever ou de "inescrever" a História. O livro funde narrativa, poesia, ensaio num tecido de brevíssimos capítulos, fragmentos da experiência coletiva, alguns deles com o efeito de um coro de tragédia grega. Dessa forma, uma rede de vozes emerge do passado e ecoa no presente, construindo pouco a pouco a história de uma família - da narradora - que é também a história de uma comunidade, da Galiza e, por extensão, da Espanha e de outros países que foram submetidos a ditaduras - no intento de recuperar uma identidade pessoal e coletiva.

O fio condutor de seique é a necessidade de saber e o dever de contar os feitos de um homem da família da narradora, o tio Manuel, irmão da avó Glória, que, diziam, havia praticado a trocidades no período da Guerra Civil e do pós-guerra, as quais ninguém da casa ou da vizinhança se atrevia a expor de forma clara e aberta, primeiro, por medo, depois, por impotência em tempos de a nistia e democracia. Os crimes do tio Manuel ta mpouco foram submetidos a exame ou julgamento e, portanto, mantêm-se encobertos, quase esquecidos, na atualidade. A partir dos "contos" que escutava principalmente das mulheres da família - avó Glória, mãe, tia Ubaldina, tia Teresa, prima Casilda - e do a madurecimento pessoal, a narradora começa a compreender os significados obscuros da história familiar em sua relação direta com os acontecimentos políticos e sociais decorrentes do golpe de estado de 1936. Entende que as atrocidades em massa cometidas contra cidadãos comuns não são apenas decorrentes da loucura ou ruindade de uma pessoa - de um Hitler, de um Videla, de um Franco, de um tio Manuel - nem de um sistema social ou político, autoritário, militarizado, patriarcalizado, mas de a mbas as realidades que se complementam, "um sistema pernicioso faz emergir das covas da terra a ruindade daquelas pessoas dispostas a viver indignas. não há violência sem agressor desumanizado. não há máfia sem sicários." (SÁNCHEZ ARINS, 2019, p.74) ${ }^{10}$

Ao longo do livro, referências aos atos nefastos cometidos por Manuel, o Montanhês, encontram-se disseminadas no "coro" de vozes que denuncia, sem, no entanto, revelar, crimes que o tio-avô teria cometido contra a própria família e contra moradores da região de Cambados: "se foi assim de mau com o pai, como seria com os de fora." [...] "se foi assim de mau com os irmãos, 
como seria com os de fora." [...] "se foi assim de mau com o cunhado, como seria com os de fora." [...] "se fora assim de mau com a família, porque não o havia de ser com os vizinhos.” [...] (p.41, p.72, p.80, p.168) Tais entreditos, que apenas insinuavam as maldades que a família silenciava com certo pudor, frequentes na casa dos avós paternos, marcaram a infância da narradora, impregnada desde sempre pelos contos da avó Glória sobre os tempos de riqueza e felicidade que precederam a Guerra Civil, antes de que o tio Manuel, o mais velho dos treze irmãos, valendo-se discricionariamente do poder que lhe conferiram os novos mandatários políticos a partir do "a no triunfal", tomasse posse da propriedade familiar, Portaris, expulsando dela os pais e os irmãos:

a avó glória sempre a falar de quando a casa grande de portaris, de como era feliz antes de acontecer o acontecido. ma mã sempre a contar da família, do importante que era, que até escudo e gótica a casa de pedra em vigo tínhamos. [...]

venho de uma família edificada em raiva, porque a míngua que vivia não era merecida. Se não fosse o tio manuel, portaris seria nosso, se não fosse aquela peleja, continuaríamos a ter domingos e parentes, se não fosse a guerra, viveria em redondela. ai, se não fosse... (SÁNCHEZ ARINS, 2019, p.18)

Note-se que, ao recuperar a história do tio Manuel, a a utora de seique revela que, ao terror dos golpistas voltado aos "vermelhos" - "o movimento depurador do povo espanhol”, na expressão do general Gonzalo Queipo de Llano -, misturava m-se indiscriminadas e cruéis ações motivadas por vingança, a mbição por terras e bens, e outras misérias huma nas e que durante o regime franquista, muitas vezes sob o disfarce de combate ao comunismo, ateísmo, maçonaria, havia projetos de enriquecimento, ações inescrupulosas em beneficio próprio cujo objetivo era acumular bens e fazenda. No caso do tio Manuel, a a mbição se volta contra a própria família, os pais e os irmãos, nem todos apoiadores da República. Como declara a narradora em "enganos":

aprendemos desde meninas que o tio Manuel roubara a herança a todos os irmãos, treze, fora os morridos.

eu imaginava o tio manuel como o tio patinhas, da disney, oculto no seu gabinete da casa grande de portaris, temeroso de que qualquer sobrinho-neto soubesse dos seus tesouros, e adicando as tardinhas e noites a falsificar escrituras avelhentar papelada e fabulando uma falsa memória que o virasse a mo e senhor de 365 ferrados, $366 \mathrm{em}$ anos bissextos. 
porém, como sempre tivemos a avó glória por mulher espilida, outra vez chegou a dificuldade para entendermos as voltas da vida. e outra vez descabia nas nossas cabecinhas como pudera ela cair na armadilha. (SÁNCHEZ ARINS, 2019, p.64)

Em 1940, Manuel Sánchez Sampayo foi nomeado prefeito de Ribadumia, município no qual se localizava a propriedade de Portaris. Como defensor do "glorioso movimento", gozou de poderes e privilégios que lhe possibilitaram "falsear partidas e testamentos com cúmplice silêncio administrativo.” (p.90) De acordo com o historiador Emilio Grandía, para os cargos administrativos, o primeiro franquismo preferiu, aos que já haviam tido um compromisso direto com a política, homens reconhecidos localmente por seu conservadorismo e oposição ao sistema implantado pela II República, isso porque o golpe militar se realizou, entre outras questões, "teniendo como funda mento básico el sacar de España toda la política, entendida de manera peyorativa." (GRANDÍO, 2001 p.224). De acordo com o historiador, esses homens, sem vinculações partidárias, realizariam uma gestão mais eficiente, pois seriam facilmente manipulados pelos dirigentes militares e assimilariam sem dificuldades os ditames do novo regime no tocante a manter a disciplina e a ordem absolutas, como determinavam os militares sublevados. Manuel, o Montanhês, roubou os pais e os irmãos, enriqueceu, apropriando-se da propriedade da família; e "matou gente. isso ta mbém recordava a vizinhança." (p.114).

Em seique, a narradora salienta a dificuldade ou a impossibilidade de encontrar provas que evidenciem a verdade dos fatos relatados pelas vítimas ou testemunhas das violências praticadas pelos sublevados, uma vez que "já se encarregaram eles de queimar informes, rachar cartas, engolir testes, afogar depoimentos judiciais, eliminar delações pera nte a utoridades, avisos de fugas alheias, declarações de fascismos próprios para que [...] não encontremos nada. nada." (p.114) Sabe-se, no entanto, que Manuel García Sampayo foi um dos mais temidos repressores franquistas da região de Salnês, na província de Pontevedra, Galiza. Seus feitos e seu nome, porém, não passaram para a história. Não há referências a Manuel em documentos, a rquivos ou jorna is locais de época, não ficaram rastros de seus atos. Nesse sentido, conclui a narradora que os vencedores não apenas escrevem a história, "mas ta mbém é certo que a inescrevem e assim o tio Manuel, que era mau e foi mau só resta nos registos da história local como alcalde de sua vila durante uns a nos. só.” (p.212) Sem documentos comprobatórios que identifiquem os repressores e seus atos a história da repressão franquista permanece incompleta, afirma 
11. No final do livro encontra-se uma bibliografia e uma webgrafia com os materiais consultados pela autora. a narradora, ao mesmo tempo em que se interroga, em "provas de acusação", sobre a (im)possibilidade de narrar:

A medida que avanço na escrita chega o outro pudor: não tenho a primeira prova documental das feitorias do tio manuel. Que conto? Como conto? Tudo quadra. a migos, da tas, lugares, mas não há documentos.

li quanto livro de história local, provincial, universal, foi caindo nas minhas mãos, perguntei a historiadores que andam a pesquisar os anos do medo na província de ponte vedra, ou na zona de salnês. nenhum deles deu com o tio manuel nas suas pesquisas. E todos confirmaram, para o meu estorvo, que não é fácil que apareçam nomes dos integrantes das brigadas passeadoras, por atuar esta à margem de tudo, mesmo da legalidade fascista.

e sem papeis que termem, e sem vozes que falem, que narrar? (SÁNCHEZ ARINS, 2019, p.97)

Os infrutíferos resultados das pesquisas bibliográficas e fílmicas ${ }^{11}$ possibilitaram, entretanto, que em seique aflorassem memórias das agressões praticadas por Sánchez Sampayo. A autora oferece aos leitores depoimentos, recordações traumáticas de pessoas que sofreram agressões ou humilhações ou tiveram familiares eliminados ou torturados pelo tio Manuel e seus sequazes - grupo de cúmplices que incluía até mesmo o padre falangista de Ceia, José Gago Tarrio -. Nomes e sobrenomes de vítimas e repressores constam no livro como uma forma de dar a conhecer, de fixar por escrito, de registrar, não só os acontecimentos brutais que marcaram a vida de milhões de espanhóis a té hoje, mas também a condição de impunidade dos repressores, que se esforçaram para não existir para a história e diluir-se na deslembrança do passado. A literatura, dessa forma, com sua dimensão poética, estética, retórica, cumpre um importante papel de reivindicação da verdade, ao aportar interrogantes, pistas e caminhos para o conhecimento e a investigação histórica. (LACAPRA, 2005, p.40) Nesse sentido, no fragmento "oito palavras", conta como, à época com apenas oito a nos, a tia Lolita assistiu ao assassinato do pai, do qual participou o próprio irmão, o tio Manuel:

chamaram à porta da taberna de madrugada. a mulher não queria abrir, mas o homem disse a frase funesta, nada temos a temer. destrancou o poxigo e encontrou a face de um fascista de camisa azul. a carão dele reconheceu, espaventado, outra boca que afirmou, alto e claro: sim, este é meu irmão. não houve tempo a mais palavras. falou a pistola e o som seco de um corpo inerte a cair. 
a tia lolita tinha oito anos e presenciou o assassinato do seu pai agachada por trás do balcão.

desde esse dia, por sempre, a tia lolita respondia os cumprimentos do seu tio com as mesmas palavras condenatórias: o senhor matou o papá, eu vim-no.

tu sonhaste! quando a menina foi moça optou por fazer mais esporádicos os encontros. e quando a moça deu em senhora, acabou exsudando remorsos em forma de enreixados por toda a casa. temia a noite escura e a vingança da sobrinha.

este conto botou-me minha mãe. (SÁNCHEZ ARINS, 2019,p.88)

Ramón García Sampayo, outro dos doze irmãos da avó Glória, ta mbém ocupou cargo de prefeito municipal, mal terminada a Guerra Civil, como se lê em "premio": "em seis de agosto de 1939, nem sequer um mês após o glorioso alça mento, entre comerciais de conhaque osborne e bombas siemens, foi anunciada a nomeação como alcalde de meis de ramón garcía sampayo, o falangista bom.” (p.133) Dizia a avó Glória que o tio Ramón teria avisado algumas pessoas que o irmão, Manuel, lhes daria o "passeio" e, assim, salvou várias vidas. A na rradora, no entanto, questiona os critérios que o falangista bom utiliza ria para selecionar aqueles que mereciam ou não ser avisados do "passeio" ou os motivos que o levaram - quando chefe local da falange de Cambados em 1956
- a negar a solicitação do professor que há vinte pedia a revisão da pena que o proibia de ministrar aulas, "a pesar do mestre estar já morto, continuou a afirmar que a sua conduta política, social e religiosa deixava bastante a desejar." (p.139). Em “ajuste de contas”, pondera a narradora:

aprendemos que por trás da violência repressiva do ano 36 andava $m$ as genreiras pessoais. velhos pleitos por uma veiga, um marco. um arrendamento devido ou excessivo no preço. uma moça arrebatada no campo da festa ou negadora da baila. uma liorta laboral. a oportunidade de um roubo. a maneira de evitar que a violência acabe com a vida própria. pode ser.

mas também sabemos que só ajustou contas privadas quem se colocou publicamente do triunfante bando e vitorioso. e aî deixaram de ser represálias íntimas.

passaram a fazer parte da política do terror. (SÁNCHEZ ARINS, 2019, p.130)

Como destaca o historiador Arnabat Mata, ao terror oficial instaurado pelos militares em 1936 contra qualquer indivíduo minimamente relacionado com as esquerdas republicanas, somava-se o terror cruel e indiscriminado que praticavam indivíduos, em sua maioria 
falangistas, imbuídos de sentimentos patrioteiros aos quais se misturavam outros tão ou mais torpes, como vinga nças e a mbições por propriedades, terras e bens:

Es la primera etapa de los "paseos" y las "sacas", en que la gente desaparece en una cuneta de carretera o en la tapia de un cementerio, en que hay actuaciones individuales, totalmente al margen de cualquier ley, tribunal o norma. Pero este terror individual forma parte del plan global y aparece con la plena $\mathrm{y}$ total tolerancia de los jefes militares. (ARNABAT MATA 2013, p.50)

Em seique, Susana Sánchez Arins procura colocar em evidência as truculentas e sanguinárias ações que instauraram o terror na Galiza desde os primeiros dias do golpe de estado, cometidas por indivíduos como o tio Manuel. Como tantos de sua laia, Ma nuel Sánchez Arins gozou ao longo da vida de um indulto para humilhar, roubar, matar sem ter nunca que preocupar-se com as consequências de seus atos perante a justiça. Ademais, a ausência de registros de suas atividades ou de denúncias de seus crimes, confere-lhe um anonimato que impossibilita qualquer tipo de investigação relacionada às práticas repressivas que executou durante o período franquista, o que significa a impossibilidade de se fazer qualquer repa ração às vítimas. Nesse sentido, ainda que a memória histórica seja uma questão política como afirma Mercedes Yusta Rodrigo (2014, p.41), a literatura contribui para romper com um dos maiores trunfos do franquismo, preservado e protegido no período democrático pelo pacto de anistia firmado durante a transição: a desmemória histórica. É o que deixa evidente Susana Sánchez Arins ao expor em seique os feitos criminosos de um homem que existia apenas na lembrança das vítimas.

Para Paul Ricoeur, o dever de esquecimento imposto pelas a nistias - como foi o caso da Espanha durante o período de transição democrática - equivale a uma amnésia comandada. Se essa a mnésia conseguisse ter êxito, a memória individual e coletiva "seria privada da saluta crise de identidade que possibilita uma reapropriação lúcida do passado e de sua carga tra umática.” (2007, p.462) Segundo o filósofo, a fronteira entre a nistia e a mnésia entendida como uma opção de esquecimento e não como uma imposição - não pode existir sem um trabalho de memória, de investigação do passado e de seus traumas, que conduza, depois do luto, a uma reconciliação.

\section{COMO CONTAR...?}

Segundo a própria Susana Arins, em entrevistas para o periódico Sermos Galiza e a página literário Lecturafilia, sua intenção, inicialmente, era escrever História ou um 
romance clássico. No entanto, encontrou o obstáculo da ausência de fontes, o que, de acordo com a autora, "é um problema em contextos como o da repressão franquista, em que as acções paralegais, como os passeios, não constam nenhures e na que os a rquivos foram limpados e saqueados e muitos dos documentos mentem mais que qualquer testemunho oral." (SÁNCHEZ ARINS apud GARRIDO, 2016) Por outro lado, conta a a utora que, ao perceber que as versões sobre os fatos mudavam à medida que ia conhecendo a história familiar, julgou que seria importante que essas variações tivessem o seu reflexo no livro, ao dar-se conta de que nos romances sobre Guerra Civil lhe incomodava "a redondeza que oculta a dificuldade pra recuperarmos as histórias, o sucesso da (des)memória fra nquista.” (SÁNCHEZ ARINS, 2016)

Como já foi dito anteriormente, Susana Arins utiliza em seique uma linguagem poética capaz de transmitir por meio de recursos como elipse, concisão, seleção lexical sugestiva e ritmos verbais - a sensação da oralidade e criar, assim, um efeito multívoco - com diferentes versões de um mesmo fato. A segunda edição do livro deixa ainda mais explícito o caráter de construção coletiva da obra ao incorporar material de memória ou documental fornecido por leitores da primeira edição. seique se compõe de brevíssimos capítulos que apresenta m, em forma de narrativa, poesia, ensaio, fragmentos da experiência comunitária que se entrelaçam numa rede de vozes que ressoa $\mathrm{m}$ do passado ao presente, construindo-se num ir e vir de versões com sucessivos acréscimos de informações, de acordo com a voz que narra. Assim, pouco a pouco, Sánchez Arins recupera aspectos escusos da história familiar e de sua identidade pessoal e cidadã.

Observem-se os seguintes fragmentos:

$$
\text { pobres de pedir }
$$

no natal o crego de lois fazia a coleta para as fa mílias sem recursos, essas de mães que não tinham filhos ou filhos que não tinham mães, aquelas que foi preciso purgar extirpando-lhes pais piolhentos de sindicalismo e sacudindo mães empulgadas de anarquismo.

um domingo que a tia ubaldina foi à missa encontrou o seu nome, waldina garcía sampayo, na listagem de vizinhas caridadas

fora o tio manuel, que pensou daná-la pondo-a por mísera. o ghinaldo

a tia ubaldina falou ao padre diante de todas as freguesas: dê-me a caridade, que ainda na recebi. mulher foi erro, todos sabemos que tu não passas penúria. esse papel diz que sou pobre, 
alguém riscou o meu nome, ninguém apagou, portanto, quero a minha porção.

imagino-a caminhando ousada, ergueita, pisando reja nas lajas do adro, avançando entre a fileira de paroquianas santigadoras, cesta na testa, com patacas, xabrão, unto, farinha milha, pinhas para prender lume.

deixando bem à vista quem era o miserento da família.

cariátide

vinha ubaldina da igreja

canastro a teigado na cabeça

eu ainda não estudara arte

coro

Se foi assim de mau com a irmã, como seria com os de fora... (SÁNCHEZ ARINS, 2019, p.105,106)

O episódio - que a narradora ouviu da prima Casilda, filha da tia Ubaldina - destaca, por meio de um tom zombeteiro, raro no livro, a rebeldia da mulher capaz de encarar com altivez e coragem uma situação que havia sido criada com a intenção de humilhá-la. Note-se como a sucessão de fragmentos informa o leitor e ao mesmo tempo leva-o a constatar como a percepção de um dado momento resgatado da memória pessoal da narradora, de uma parenta sua e também da coletividade (é o que sugere o título "coro", no último fragmento transcrito) se forma pela justaposição e interpenetração de pontos de vista dispersos no tempo: o primeiro fragmento transcrito informa sobre o hábito do padre local de organizar uma lista de doações para as famílias mais pobres. Já nesse fragmento se tematiza a Guerra Civil e suas consequências nefastas, pois muitos dos necessitados o são em decorrência das perseguições e depurações franquistas, que haviam eliminado "pais piolhentos de sindicalismo" e "mães empulgadas de a na rquismo", deixando órfãs muitas crianças. Tia Ubaldina teve seu nome incluído nessa lista pelo irmão, é o que narra sua filha Casilda - e a finalidade dessa inclusão era humilhá-la. Sua reação, no entanto, foi inesperada e altiva e é contada no fragmento seguinte, "o ghinaldo", no qual se exploram os ritmos da língua falada no breve diálogo aí apresentado e na agilidade da imaginação da voz narrativa, que caracteriza o traje e as ações da personagem Ubaldina numa sequência de forte visualidade, uma verdadeira sucessão de flashes à maneira cinematográfica. O fragmento seguinte, "cariátide”, remete a uma avaliação do episódio narrado, feita pela voz narrativa a partir de um conhecimento posterior adquirido sobre a escultura clássica: a tia Ubaldina que fora recolher sua esmola à igreja se eleva à condição de cariátide grega, coluna de sustentação esculpida com as formas de uma figura feminina. Desse modo, confere-se à a titude da tia Ubaldina uma elevação moral 
capaz de torná-la referência, ou seja, sua conduta digna se torna exemplar. No fragmento seguinte, "coro", outra menção ao mundo clássico: a voz coletiva se afirma no texto como a voz da pólis no tea tro grego - e o coro joga sobre os fatos narrados seu veredito baseado nas normas de convivência da coletividade, o mundo da - literalmente - política.

Esse modo de contar confere à matéria narrada uma configuração que sugere o modo como se vai constituindo o conhecimento do mundo que se quer obter com os esforços de reconstrução de um passado indocumentado como é o que Susana se propõe a moldar. São fragmentos que se atritam com outros fragmentos, com dados de momentos posteriores, com avaliações buscadas em outros universos referenciais - e o que se vem a mostrar ao leitor é um mundo que, se surge impregnado de incerteza e lacunas, não deixa de ter contundência e de representa a dor e a indignação diante da dor causada pela injustiça. É seu modo de ser verdadeiro - o modo literário, já que o histórico - tomado o termo aqui no sentido documental - não foi criado ou foi intencionalmente desfeito.

\section{BIBLIOGRAFIA}

Arnabat Mata, Ramón. "La represión: el ADN del franquismo español". Cuadernos de historia (Santiago) No39, Santiago, dic. 2013.

CONSTENLA, Tereixa. "La maldad no tiene derecho a anonimato. La escritora Susana Sánchez Arins rastrea en 'Dicen' la historia del personaje más sombrío de su familia". El País, Madrid, 28/04/ 2019, Cultura.

Espinosa Maestre, Francisco (ed.). Violencia roja y azul. España, 1936-1950. Barcelona: Crítica, 2010

GARRIDO, X.C. "Se fez isso aos da casa que faria aos de fora". Nòs Diario, Santiago de Compostela, 10/08/2016, Memoria e Historia. Disponível em: nosdiario.gal/ articulo/memoria/fez-isso-aos-da-casa-faria-aosfora/20160809140840050173.html

GÓMEZ BRAVO, Gutmaro. "Claves del modelo penitenciario franquista (1939-1948)". Revista de Estudios Extremeños Badajoz, Tomo LXVII, No II, 2011

JUNOUEIRA, Natalia. "Los asesinos no solo mataron. Hallados en Barro las pruebas de un brutal asesinato cometido en 1936". El País, 22/10/2009, Galicia. 
LACAPRA, Dominick. Escribir la historia. Escribir el trauma. $1^{\mathrm{a}}$ ed. Trad. Elena Marengo. Buenos Aires: Nueva Visión, 2005

RICOEUR, Paul. A memória, a história, o esquecimento. Tradução de Alain François [et al.]. Campinas: Editora da Unicamp, 2007.

SÁNCHEZ ARINS, Susana. aquiltadas. Sacauntos: Estaleiro, 2012

seique. $1^{\mathrm{a} e d}$. [Santiago de Compostela]: Através Editora, 2015

seique. $2^{\mathrm{a} e d}$. revista e ampliada. [Santiago de Compostela]: Através Editora, 2019.

"Entrevista Susana Sánchez Aríns: 'Acho essencial pôr sobre a mesa, duma vez, após mais de oitenta anos, a questão dos repressadores". Lecturafilia. Ler es vivir dos veces, 02/06/2018. Disponível em: lecturafilia.com/tag/ entrevista-susana-sanchez-arins/
TORRES, Ramiro, "Entrevista a Susana Sánchez Arins". Palavra Comum. Revista Galega de Artes e Letras. A

Coruña, 15/02/2015. Disponível em: palavracomum.com/ entrevista-a-susana-sanchez-arins/

VILAVEDRA FERNÁNDEZ, Dolores. "Memoria y postmemoria: la elaboración literaria de la Guerra Civil en la narrativa gallega". In: Gerhardt, Federico (Ed.). Representaciones del pasado reciente: II República, Guerra Civil, exilio, posguerra. La Plata, FAHCE-UNLP, 2011. Disponível em: sedici.unlp.edu.ar/handle/10915/31627

YUSTA RODRIGO, Mercedes. "El pasado como trauma". Pandora: revue d'etudes hispaniques, Paris, $N^{\circ} 12$ 2014, p. 23-41.

Zubiaga Arana, Erik. "¿Holocausto, genocidio, exterminio politicidio...? Conceptualizaciones sobre el desarrollo de la represión franquista. Especial atención al caso vasco." In: Colomer Rubio, Juan Carlos; Martí, Javier Esteve;

Ibáñez Domingo, Mélanie (coords.). Ayer y hoy. Debates, historiografía y didáctica de la historia. Valencia:

Universitat de València, 2015.

Recebido em:14-02-2020

Aceito em:11-05-2020 